Article

\title{
Synthesis, Properties of Biodegradable Poly(Butylene Succinate-co-Butylene 2-Methylsuccinate) and Application for Sustainable Release
}

\author{
Jiarui Han, Jiaxin Shi, Zhining Xie, Jun Xu* and Baohua Guo * \\ Key Laboratory of Advanced Materials of Ministry of Education of China, Department of Chemical Engineering, \\ Tsinghua University, Beijing 100084, China; chaxiangmeimei@163.com (J.H.); shijx13@tsinghua.org.cn (J.S.); \\ xiezhining@126.com (Z.X.) \\ * Correspondence: jun-xu@mail.tsinghua.edu.cn (J.X.); bhguo@mail.tsinghua.edu.cn (B.G.)
}

Received: 10 April 2019; Accepted: 7 May 2019; Published: 9 May 2019

\begin{abstract}
A novel biobased and biodegradable polyester, i.e., poly(butylene succinate-co-butylene 2-methylsuccinate) (P(BS-BMS)) was synthesized by succinic acid (SA), 2-methylsuccinic acid (MSA), and 1,4-butanediol (BDO) via a typically two-step esterification and polycondensation procedure. The chemical structure and macromolecular weight of obtained copolymers were characterized by ${ }^{1} \mathrm{H}$ NMR, ${ }^{13} \mathrm{C}$ NMR, and GPC. The melting temperature and degree of crystallinity were also studied by DSC, and it was found that the values were gradually decreased with increasing of MSA content, while the thermal stability remained almost unchanged which was tested by TGA. In addition, the biodegradation rate of the $\mathrm{P}$ (BS-BMS) copolymers could be controlled by adjusting the ratio of SA and MSA, and such biodegradability could make P(BS-BMS) copolymers avoid microplastic pollution which may be brought to the environment for applications in agricultural field. When we applied $\mathrm{P}$ (BS-BMS) copolymers as pesticide carriers which were prepared by premix membrane emulsification (PME) method for controlling Avermectin delivery, an improvement of dispersion and utilization of active ingredient was obviously witnessed. It showed a burst release process first followed by a sustained release of Avermectin for a long period, which had a great potential to be an effective and environmental friendly pesticide-release vehicle.
\end{abstract}

Keywords: biodegradable copolyesters; crystallinity; degradation property; pesticide-loaded microparticles; pesticide release

\section{Introduction}

Nowadays, in view of the threat of environmental pollution and resource shortage to sustainable ecological construction, fully biobased and biodegradable materials becomes an urgent issue in both academic and industrial fields [1-4]. As a result of this increasing attention, numerous renewable polymers including thermoplastic [5], thermoset [6,7], and vitrimers [8,9] with multiple complex performance have been developed in order to replace traditional petroleum-based materials. Among these sustainable polymers, in view of the excellent biodegradability [10-17], poly(butylene succinate) (PBS) and its copolymers [18-20] are widely used in different fields such as agriculture [21,22], food packages [23], and hygiene products [24]. Bi, et al. [25] investigated the relationship between the rate of enzymatic degradation and the ratio of butanediol to hexanediol in the poly(butylene succinate-co-hexamethylene succinate). This kind of copolymers shows a great potential as a sustainable substitute with tunable enzymatic degradation in agriculture and packaging industries. Besides the biodegradable property, for meeting the different requirements of application, the chemical structures of PBS are usually modified by copolymerization with a third monomer such as terephthalic acid $[26,27]$ 
(diacids), hexanediol [28] (diols), and other functional monomers [29,30]. Generally, the crystallization property of the polymer is a crucial factor, which can be flexibly controlled by copolymerization [31,32]. Zhang, et al. [33] discussed the interplay between the Diels-Alder reaction and crystallization in poly(2,5-furandimethylene succinate)-b-poly(butylene succinate) (PFS-PBS) multiblock copolyesters. The PFS-PBS copolymers can be adjusted flexibly from soft to rigid materials by controlling the PFS content. Zheng, et al. [34] demonstrated a multiblock copolymer composed of poly(butylene succinate) (PBS) and poly(butylene fumarate) (PBF) which could provide various reactive sites on the main chain for further modification. It showed an isomorphic cocrystallization phenomenon in PBS-PBF block copolymers. As an economically viable renewable build unit, itaconic acid (IA), and its derivatives get more exploration [35-37]. Trotta, et al. [3] reported a novel thermoplastic which was almost completely derived from IA while high atom economies and mild process conditions for reaction procedure indicates "green process". 2-methylsuccinate acid (MSA) which can be simply produced by catalytic hydrogenation of IA owns similar structure with SA [38]. Wu, et al. [39] declared a novel aliphatic polyester synthesized from MSA and BDO, which displayed desirable mechanical property and superior migration resistant property as bio-based polymeric plasticizer. The similar structure leads to the potential to regulate the crystallinity of PBS chains by introduction of MSA. Since it can flexibly adjust the properties of synthetic copolyesters like crystallization, stability, and biodegradation by changing the type of copolymerization units and the copolymerization ratio to expand the material application fields, synthetic copolyesters have been taken close attention of many researchers.

The use of fully biobased and biodegradable polymers in agriculture field has increased dramatically in recent years throughout the world due to possessing equal performance while not putting pressure on the environment like white pollution [40-44]. For example, numerous degradable polymers including natural ones like starch and synthetic ones like poly(butylene adipate-co-terephtalate) (PBAT), polylactic acid (PLA), poly(3-hydroxybutyrate) (P3HB) and poly(butylene succinate) (PBS) have been applied rather than polyethylene as agriculture mulch $[45,46]$. Zhang, et al. [29] introduced a kind of UV absorber 2-hydro-4-(2,3-epoxypropoxy) benzophenone (HEPBP) into PBS chains via polycondensation. This functional PBS owned excellent UV protection effect as agriculture mulch use. Lubkowski, et al. [47] illustrated a controlled-release multicomponent fertilizer coated with a biodegradable copolymer consisting of poly(butylene succinate) and a butylene ester of dilinoleic acid. A conceptual model describing the release of nutrient through the coated layer was presented. In addition, the protection and efficient use of pesticides is another challenge for agriculture [48-51]. Traditional formulations usually use a large amount of organic solvent and dispersants in order to enhance the dispersibility of hydrophobic pesticide components, consequently posing a serious threat to food safety and ecological environment [52]. Furthermore, owing to the instability properties of pesticides and traditional pesticide formulations which include photolysis, evaporation, and surface slip, the active ingredient content in conventional formulations is rapidly consumed, falling below the effective level after an initial burst release. In order to improve the shortcomings of traditional pesticide formulations, researchers have conducted extensive research on pesticide carriers. Jia, et al. [53] demonstrated a novel polydopamine microcapsule containing Avermectin prepared by in situ emulsion interfacial polymerization. Experimental results showed the excellent sustained-release of active ingredient and good adhesive performance on plants leaves. $\mathrm{Li}$ et al. [54] illustrated the preparation of uniform starch microparticles containing Avermectin via premix membrane emulsification (PME) method. The effects of microparticle size, Av content, and carrier morphology on release performance were investigated in this work. PME is well known as a mild technique to produce stable emulsion with highly uniform droplets while expending relatively low energy input. Therefore, it is widely used in medicine, painting, cosmetics, and other industries [55-59].

Herein, we applied a novel kind of biobased and biodegradable copolymer poly(butylene butylene succinate-co-2-methylsuccinate) (P(BS-BMS)) in pesticide release field which has not been reported. We introduced MSA monomer instead of part of SA unit in the normal polycondensation process to regulate the chain structure in order to tune the properties, especially crystallization and 
biodegradability of copolymers, which have a significant impact on evaluation of pesticide carrier like drug loading, releasing rate, and environmental pollution. Furthermore, a model drug Avermectin (Av) was encapsulated in the uniform P(BS-BMS) microparticles by PME method. The effect of copolymer crystallinity on the morphology of Av-loaded microparticles and performance of Av release was revealed. Based on such the environmental-friendly property and optimal drug loaded performance, $\mathrm{P}(\mathrm{BS}-\mathrm{BMS})$ is a kind of promising materials as pesticide delivery carrier in the pesticide application field.

\section{Experimental Section}

\subsection{Materials}

2-methylsuccinic acid (MSA, >99.0\%) was provided by Shenzhen VTOLO Industrial Co., Ltd, Shenzhen, China. 1,4-butanediol (BDO, $>99.5 \%$ ) and succinic acid (SA, purity $>99.5 \%$ ) were supplied by Tianjin Jinke Fine Chemical Research Institute and Anqing Hexing Chemicals Co., Ltd. (Anqing, China), respectively. Poly(vinyl alcohol) (PVA1788, 87.0-89.0\% hydrolyzed with an average $M_{\mathrm{w}}$ of 30,000-70,000) was purchased from Aladdin Industrial Corporation. Avermectin (Av, Qilu Pharmaceutical (Inner Mongilia) Co., LTD., Inner Mongolia, China, 95\%) and Avermectin EC (Hebei Weiyuan Chemical Co., Ltd, Shijiazhuang, China, $5 \mathrm{wt} \%$ ) were obtained. Methanol (HPLC Grade, 99.9\%) was supplied by J\&K Scientific Ltd. (Shanghai, China). Other reagents and solvents (AR grade) were used directly without any purification.

\subsection{Synthesis of $P(B S-B M S)$ Copolyesters}

$\mathrm{P}$ (BS-BMS) copolyesters were synthesized through a two-stage process including direct esterification and melt polycondensation. First, predetermined amount of SA, MSA, and BDO were added into a three-necked flask and heated to $135^{\circ} \mathrm{C}$ with continuing mechanical agitation in $\mathrm{N}_{2}$ atmosphere. Then, the temperature was raised to $225^{\circ} \mathrm{C}$ gradually step by step in order to make the esterification reaction sufficiently. When there was no more water produced, the temperature was decreased to $150{ }^{\circ} \mathrm{C}$ and a certain amount of catalyst tetrabutyl titanate was added with stirring for $5 \mathrm{~min}$ followed by the polycondensation proceeded at a pressure $<100 \mathrm{~Pa}$ for half an hour. Thereafter, maintaining the vacuum, the temperature was raised to $230{ }^{\circ} \mathrm{C}$ to continue the reaction for $2-4 \mathrm{~h}$ until a Weissenberg effect was observed. After the polymerization process, the samples were dissolved in chloroform, precipitated in cold methanol and then dried in vacuum oven at $40^{\circ} \mathrm{C}$ for $24 \mathrm{~h}$. The copolymers thus synthesized were denoted as $\mathrm{P}(\mathrm{BS}-\mathrm{BMS}) \mathrm{x} \%$, where $\mathrm{x} \%$ represents the molar percentage of MSA based on all diacid monomers, that is, $x \%=$ MSA $/(S A+M S A) \times 100 \%$. $\mathrm{P}(\mathrm{BS}-\mathrm{BMS}) 10 \%, 20 \%, 30 \%, 50 \%$, and pure PBS were prepared via this method.

\subsection{Preparation of the Av-Loaded P(BS-BMS) Microspheres}

The typical process for preparing the Av-loaded microsphere and blank microspheres by premix membrane emulsification (PME, National Engineering Research Center for Biotechnology) is briefly described as follows. First of all, $4 \mathrm{~mL}$ of chloroform solution containing a certain amount of P(BS-BMS) copolyester and $\mathrm{Av}$ active compound was poured into a large volume of $0.5 \mathrm{wt} \%$ PVA aqueous solution under mechanical stirring to prepare a primary emulsion. Then the primary emulsion was forced through the Shirasu Porous Glass membrane (SPG membrane) three times at a $\mathrm{N}_{2}$ pressure of $0.25 \mathrm{MPa}$. The emulsion was obtained and evaporated in $30^{\circ} \mathrm{C}$ water bath oscillator overnight. Finally, the solid microspheres were collected through centrifugation and washed 3 times with deionized water. The washed microspheres were freeze-dried for $24 \mathrm{~h}$ to obtain solid powder.

\subsection{Polymer Characterizations}

The ${ }^{1} \mathrm{H}$ NMR and ${ }^{13} \mathrm{C}$ NMR spectra were obtained by a fully automated NMR spectrometer (JEOL, ECA-600M, Tokyo, Japan), using deuterated chloroform as solvent. The molecular weight and dispersity (Đ) were measured by gel permeation chromatography (GPC) (Waters 1515, Waters, Milford, 
MA, USA) equipped with a differential-refractometer detector. The measurements were taken at $35^{\circ} \mathrm{C}$ and the chloroform was used as the eluent with a flow rate of $1.0 \mathrm{~mL} / \mathrm{min}$. The number and weight average molecular weight was calculated by using a calibration curve with monodisperse polystyrene as standards.

Differential scanning calorimetry (DSC, TA equipment, Q 2000, TA Instruments, New Castle, DE, USA) was used to determine $T_{\mathrm{m}}$ values and analyze the crystallization property of copolymer samples with different MSA percentage. The samples $(3-5 \mathrm{mg})$ were sealed in aluminum crucibles and first heated to $150{ }^{\circ} \mathrm{C}$ followed by keeping isothermal for $10 \mathrm{~min}$ to eliminate the thermal and reaction history under $\mathrm{N}_{2}$ atmosphere. After that, the samples were cooled to $-50^{\circ} \mathrm{C}$ at a rate of $-10{ }^{\circ} \mathrm{C} / \mathrm{min}$, and reheated to $150^{\circ} \mathrm{C}$ at a rate of $10^{\circ} \mathrm{C} / \mathrm{min}$. The thermal decomposition behavior was performed with a Shimadzu DTG-60 thermo gravimetric analyzer (Kyoto, Japan). Each sample (8-10 mg) was heated from $30^{\circ} \mathrm{C}$ to $600{ }^{\circ} \mathrm{C}$ at $10^{\circ} \mathrm{C} / \mathrm{min}$ in $\mathrm{N}_{2}$ atmosphere with a flow rate of $40 \mathrm{~mL} / \mathrm{min}$. The crystal structure of P(BS-BMS) copolymers was measured by wide-angle X-ray diffraction (WAXD, BrukerD8 Advance, Bruker, Hamburg, Germany) in powder diffraction mode. The samples were melted and prepared to films for testing. Scanning was performed with $2 \theta$ from 5 to $40^{\circ}$ with a step of $0.02^{\circ}$.

\subsection{In Vitro Degradation Test}

$\mathrm{P}$ (BS-BMS) copolymer films were prepared by hot pressing method and then stored at room temperature at least $24 \mathrm{~h}$. The $2 \mathrm{mg} / \mathrm{mL}$ enzyme degradation test solution was prepared by dissolving a certain amount of amano lipase from Pseudomonas fluorescens in the phosphate buffer saline (pbs, pH 7.2-7.4), and the enzyme-free pbs solution was used as the controls. The film samples $(10 \mathrm{~mm} \times 10 \mathrm{~mm} \times 0.2 \mathrm{~mm})$ were immersed in $10 \mathrm{~mL}$ degradation solutions and incubated at $37^{\circ} \mathrm{C}$ with continuous shaking at $100 \mathrm{rpm}$. The films were removed from the solution every 2 days, rinsed with deionized water and freeze-dried for $12 \mathrm{~h}$. The degradation solution was refreshed after each measurement. The degradation degree was quantified as weight loss and the surface morphology of these samples were observed using field emission scanning electron microscopy (FESEM, JSM-7401, JEOL, Tokyo, Japan). For SEM test, an accelerating voltage of $3 \mathrm{kV}$ was applied, and the sample was sputtered with platinum prior to the test.

\subsection{Characterizations of Av-Loaded Microspheres}

The morphology of Av-loaded microspheres was also observed by FESEM (JSM-7401). Sample preparation and operating conditions are similar to the above mentioned. The particle size and size distribution were obtained by counting statistics of SEM graphs, using Nano Measurer software (Version 1.2.0.0). And the particle size distribution was calculated according to the following equations:

$$
\begin{gathered}
D_{n}=\sum n_{i} D_{i} / \sum n_{i} \\
D_{w}=\sum n_{i} D_{i}^{4} / \sum n_{i} D_{i}{ }^{3} \\
P D I=D_{w} / D_{n}
\end{gathered}
$$

The crystal structure of Av and Av-loaded microspheres was measured by wide-angle X-ray diffraction in powder diffraction mode. The samples were ground and placed in sample cell for testing. Scanning was performed with $2 \theta$ from 5 to $40^{\circ}$ with a step of $0.02^{\circ}$. For the determination of the drug loading content, briefly, approximately $5 \mathrm{mg} \mathrm{Av}$-loaded microspheres were fully ground and dispersed in $8 \mathrm{~mL}$ methanol, then sonicated for a sufficient period of time to ensure that all active ingredients were leached. Finally, the dispersion was filtered to form a clear Av solution before analysis. The loading content (LC) and entrapment efficiency (EE) of Av were measured by high-performance liquid chromatography (HPLC, Shimadzu 16, Kyoto, Japan) using a C18 column with column temperature of $30^{\circ} \mathrm{C}$. The methanol/water (90/10) mixture was served as the elution with a rate of $1 \mathrm{~mL} / \mathrm{min}$ and the signal was detected at $245 \mathrm{~nm}$. The Av standards were used for calibration 
curve, which were created by diluting a stock solution of $500 \mu \mathrm{g} / \mathrm{mL}$ to $200,120,80,40,20,15,10$, $5,2 \mu \mathrm{g} / \mathrm{mL}$, respectively. The loading content and entrapment efficiency were calculated using the following equations:

$$
\begin{aligned}
& L C(w t \%)=\frac{\text { weight of pestiside in microspheres }}{\text { weight of microspheres }} \times 100 \% \\
& E E(w t \%)=\frac{\text { weight of pestiside in microspheres }}{\text { initial weight of pesticide fed }} \times 100 \%
\end{aligned}
$$

\subsection{Release Kinetics of $A v$}

To evaluate the release of the entrapped Av from the microspheres, a $4 \mathrm{~mL}$ of certain amount $\mathrm{Av}$ suspension in a methanol/water $(40 / 60, v / v)$ mixture was loaded into the dialysis membrane. Then the membrane bag was put into a wild-mouth flask containing $96 \mathrm{~mL}$ release media consisting of $40 \mathrm{v} \%$ methanol and $60 \mathrm{v} \%$ water. The flask was then transferred to the incubator shaker with a speed of $120 \mathrm{rpm}$ at $30^{\circ} \mathrm{C}$. At regular time intervals, $4 \mathrm{~mL}$ solution was collected and $4 \mathrm{~mL}$ fresh solvent was added into the flask back. The concentration of Av released was also determined by HPLC with the same condition above.

\section{Results and Discussion}

\subsection{Synthesis and Characterization of P(BS-BMS) Copolymers}

MSA was introduced in order to adjust the chain structure of copolymer by a classical two stage procedure as shown in Scheme 1. At first direct esterification stage, BDO could react with both SA and MSA to form ester bonds as the temperature rises. Then the P(BS-BMS) copolymers were produced via further melt polycondensation. The molecular weight and dispersity (Đ) of $\mathrm{P}(\mathrm{BS}-\mathrm{BMS})$ copolymers are listed in Table 1 and the GPC curves are shown in Figure 1. The P(BS-BMS) copolymers which owned similar $M_{\mathrm{n}}\left(5.1 \times 10^{4}-6.4 \times 10^{4} \mathrm{~g} / \mathrm{mol}\right)$ and $Đ(1.64-1.74)$ were obtained by same synthesis procedure above.

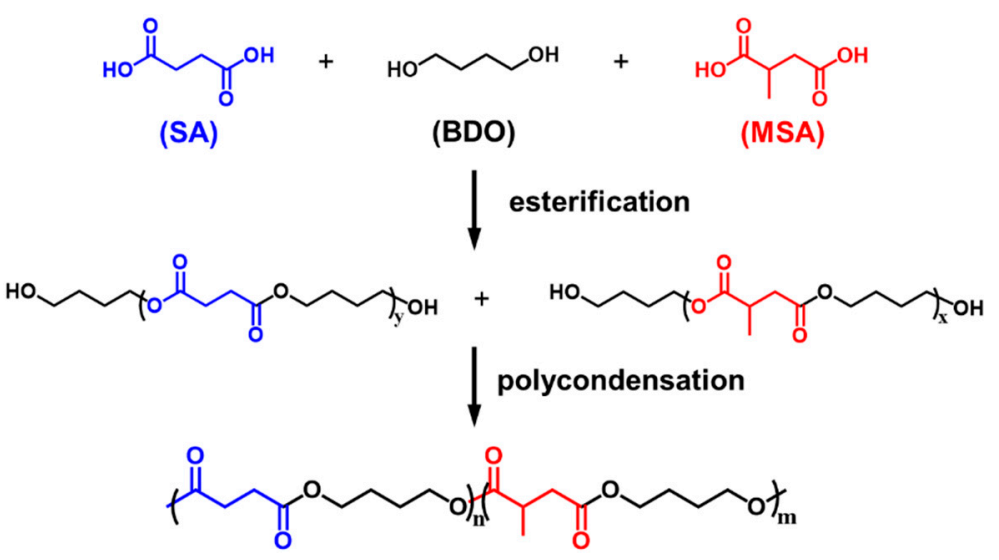

Scheme 1. Synthesis route of poly(butylene succinate-co-butylene 2-methylsuccinate) (P(BS-BMS)) copolymers. SA: succinic acid; BDO: 1,4-butanediol; MSA: 2-methylsuccinic acid.

\begin{tabular}{|c|c|c|c|c|c|c|c|c|}
\hline Polymer & $\begin{array}{l}\text { MSA } \\
(\mathrm{mol})\end{array}$ & SA (mol) & $\begin{array}{l}\text { BDO } \\
(\mathrm{mol})\end{array}$ & $\begin{array}{c}\text { Theoretical Content } \\
\text { of PBMS }(\%)\end{array}$ & $\begin{array}{c}\text { Experimental } \\
\text { Content of PBMS (\%) }\end{array}$ & $M_{\mathrm{n}}\left(10^{-4} \mathrm{~g} / \mathrm{mol}\right)$ & $M_{\mathrm{w}}\left(10^{-4} \mathrm{~g} / \mathrm{mol}\right)$ & $\boxplus$ \\
\hline PBS & - & 0.2 & 0.24 & 0 & 0 & 6.3 & 10.7 & 1.70 \\
\hline P(BS-BMS)10\% & 0.02 & 0.18 & 0.24 & 10.0 & 9.5 & 5.5 & 9.5 & 1.73 \\
\hline P(BS-BMS)30\% & 0.06 & 0.14 & 0.24 & 30.0 & 29.1 & 5.5 & 9.4 & 1.71 \\
\hline P(BS-BMS)50\% & 0.1 & 0.1 & 0.24 & 50.0 & 48.5 & 6.4 & 10.5 & 1.64 \\
\hline
\end{tabular}

Table 1. Composition and molecular weight of P(BS-BMS) copolymers and pure PBS. 


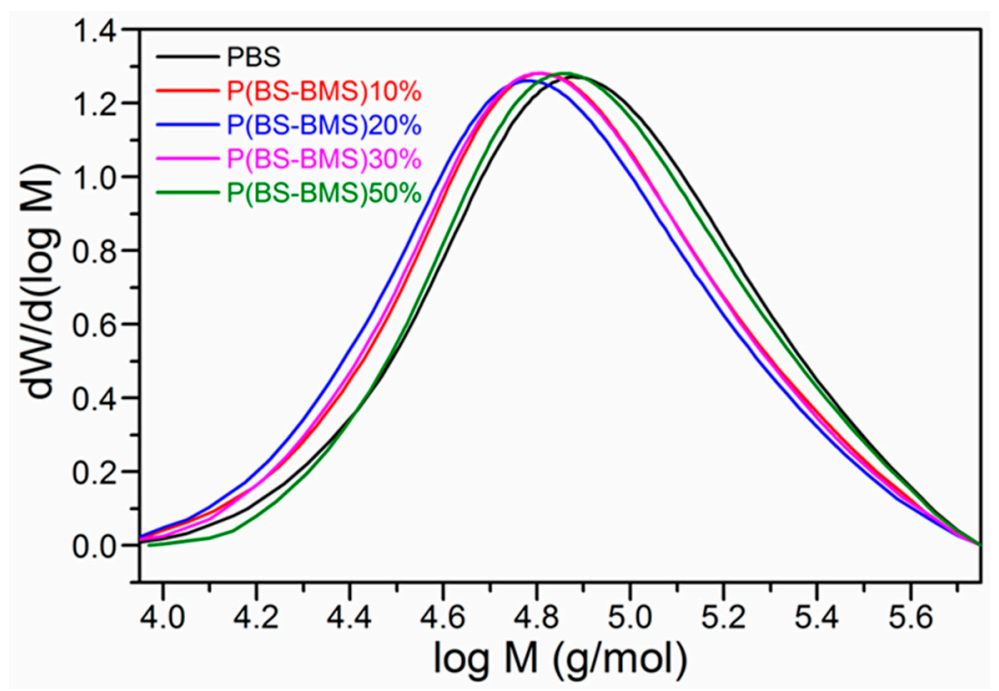

Figure 1. Gel permeation chromatography (GPC) curves of P(BS-BMS) copolymers and pure poly(butylene succinate) (PBS).

The ${ }^{1} \mathrm{H}$ NMR spectra of P(BS-BMS) $50 \%$ and pure PBS are shown in Figure 2a. For pure PBS, the peak at 4.10 and $1.69 \mathrm{ppm}$ are attributed to the protons in $\mathrm{BDO}\left(\delta \mathrm{H}^{5}\right.$ and $\left.\delta \mathrm{H}^{6}\right)$ segments, while the chemical shift of $\mathrm{CH}_{2}$ in $\mathrm{SA}\left(\delta \mathrm{H}^{7}\right)$ appears at $2.61 \mathrm{ppm}$. As the proportion of MSA increases, characteristic peaks belonging to MSA $\left(\delta \mathrm{H}^{2}, \delta \mathrm{H}^{3}, \delta \mathrm{H}^{4}\right.$, and $\left.\delta \mathrm{H}^{1}\right)$ are detected around $2.88,2.73,2.40$, and $1.20 \mathrm{ppm}$, and the increase of $\delta \mathrm{H}^{1}$ intensity is shown in Figure $2 b$. The actual compositions of $\mathrm{P}$ (BS-BMS) copolymers were calculated from the integrated area of peaks at $1.20 \mathrm{ppm}\left(\delta \mathrm{H}^{1}, \mathrm{MSA}\right)$ and $2.61 \mathrm{ppm}\left(\delta \mathrm{H}^{7}, \mathrm{SA}\right)$ according to the following equations:

$$
\begin{aligned}
f_{P B S} & =\frac{A_{2.61} / 4}{A_{1.20} / 3+A_{2.61} / 4} \\
f_{P B M S} & =\frac{A_{1.20} / 3}{A_{1.20} / 3+A_{2.61} / 4}
\end{aligned}
$$

where A represents the corresponding peak intensity, and the calculated results are listed in Table 1 , as well as the feeding proportion and theoretical content of PBMS. It can be seen that the actual composition is not much different from the feed ratio, indicating that the content of PBMS in copolymers can be accurately controlled by adjusting the feed ratio.

(a)

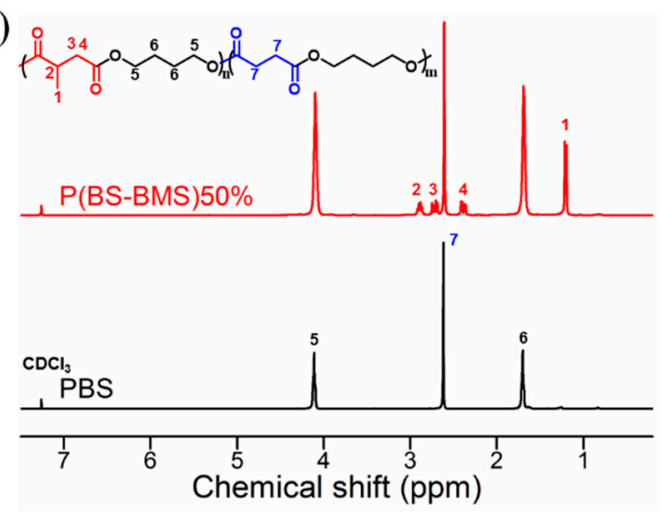

(b)

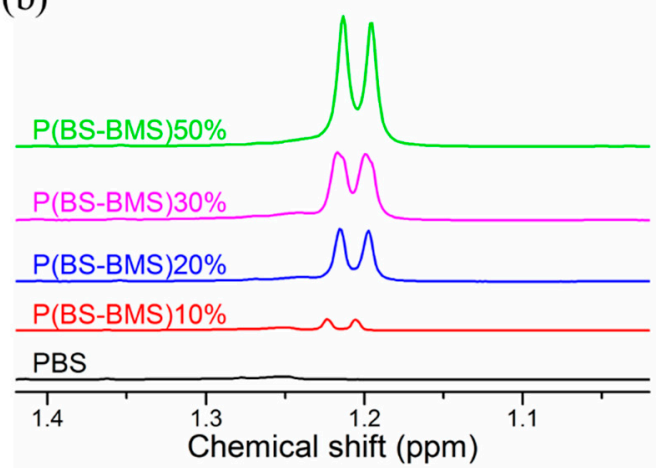

Figure 2. (a) ${ }^{1} \mathrm{H}$ NMR spectra of pure $\mathrm{PBS}$ and $\mathrm{P}(\mathrm{BS}-\mathrm{BMS}) 50 \%$; (b) ${ }^{1} \mathrm{H}$ NMR spectra of pure $\mathrm{PBS}$ and $\mathrm{P}(\mathrm{BS}-\mathrm{BMS})$ copolymers at $1.20 \mathrm{ppm}$.

Generally, the sequence distribution of copolymers has a large influence on the physical and chemical properties. ${ }^{1} \mathrm{H}$ NMR and ${ }^{13} \mathrm{C}$ NMR spectroscopies can provide detail and quantitative 
information about nature of linkages and sequence distribution to analyze and verify the relationship between performance and structure of copolymers [60-63]. When the connection at either sides of target unit changes, the environment of protons and carbon inside the unit are affected and the chemical shift changes to some extent, while the characteristic peak are split into multiple peaks in copolymers. The greater difference in linkage units, the more pronounced the split. In P(BS-BMS) copolymer structures, there are four possible environments for ethylene units in BDO: the homo unit, SS and MSMS, and the hetero unit, SMS and MSS, where $S$ and MS represented the SA and MSA, respectively. Unfortunately, in the ${ }^{1} \mathrm{H}$ NMR spectra, the peak split at $4.10 \mathrm{ppm}$ and $1.69 \mathrm{ppm}$ belonging to BDO are not very obvious, owing to the similarity of SA and MSA which makes the hydrogen environment change weakly. ${ }^{13} \mathrm{C}$ NMR spectra of P(BS-BMS) $50 \%$ and pure PBS obtained from the quantify model are shown in Figure $3 a$, the signals at $172.4 \mathrm{ppm}\left(\delta C^{5}\right)$ and $29.1 \mathrm{ppm}\left(\delta \mathrm{C}^{8}\right)$ are attributed to the carbonyl and methylene in SA unit. As the MSA monomer increased, the new peaks belonging to MSA $\left(\delta \mathrm{C}^{1}, \delta \mathrm{C}^{2}, \delta \mathrm{C}^{3}\right.$, and $\left.\delta \mathrm{C}^{4}\right)$ are detected around $175.4,37.6,35.9$, and $17.2 \mathrm{ppm}$, respectively. There is also a peak (around $171.9 \mathrm{ppm}$ ) next to the chemical shift of the carbonyl peak in the SA unit, which is assigned to the carbonyl carbon away from the methyl group in MSA. In addition, the two peaks appear at $63.3 \mathrm{ppm}$ and $25.4 \mathrm{ppm}$, which are attributed to the methylene in $\mathrm{BDO}\left(\delta \mathrm{C}^{6}\right.$ and $\delta C^{7}$ ). The characteristic peak changes of $\delta C^{6}$ in P(BS-BMS) copolymers are shown in Figure $3 b$, the carbon peak split into triple peak around 64.3-64.2 ppm clearly and assigned to SS, SMS(MSS), MSMS, respectively. By the ${ }^{1} \mathrm{H}$ NMR spectra analysis and carbon peak split of BDO, it is confirmed that $\mathrm{P}$ (BS-BMS) copolymers are synthesized successfully. These integrated resonance intensities $\left(f_{\mathrm{SS}}, f_{\mathrm{SMS}}\right.$, $f_{\text {MSMS }}$ ) are employed to calculate the sequence length of PBS and PBMS segments and stereoregularity of $\mathrm{P}(\mathrm{BS}-\mathrm{BMS})$ copolymers as the following equations:

$$
\begin{gathered}
L_{\mathrm{n}, \mathrm{PBS}}=1+2 f_{\mathrm{SS}} / f_{\mathrm{SMS}} \\
L_{\mathrm{n}, \mathrm{PBMS}}=1+2 f_{\mathrm{MSMS}} / f_{\mathrm{SMS}} \\
R=1 / L_{\mathrm{n}, \mathrm{PBS}}+1 / L_{\mathrm{n}, \mathrm{PBMS}}
\end{gathered}
$$

where $L$ represents the sequence length of PBS and PBMS, and $R$ represents the degree of randomness, respectively. The calculated results are listed in Table 2, and the $R$ values of $\mathrm{P}(\mathrm{BS}-\mathrm{BMS})$ copolymers are close to 1, which indicates the P(BS-BMS) copolymers with random structure were obtained.

(a)

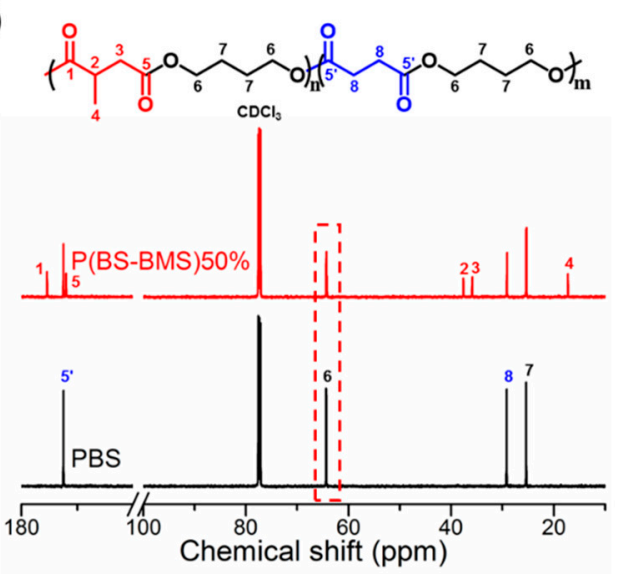

(b)

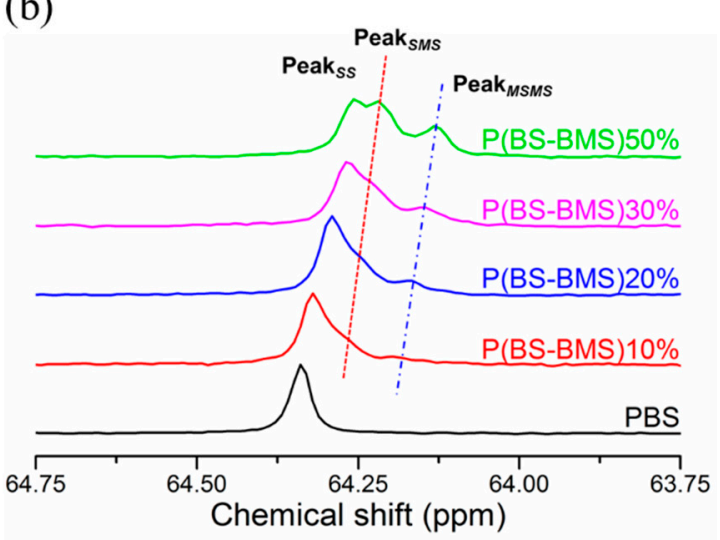

Figure 3. ${ }^{13} \mathrm{C}$ NMR spectra of (a) pure PBS and P(BS-BMS)50\%; (b) pure PBS and P(BS-BMS) copolymers around 64.3-64.2 ppm attributed to $\delta \mathrm{C}^{6}$. The data were measured in $\mathrm{CDCl}_{3}$ in $25^{\circ} \mathrm{C}$. 
Table 2. Sequence distribution analysis of $\mathrm{P}(\mathrm{BS}-\mathrm{BMS})$ copolymers.

\begin{tabular}{lcccccc}
\hline Copolymer & $f_{\text {SS }} \mathbf{( \% )}$ & $f_{\text {SMS }} \mathbf{~ ( \% )}$ & $f_{\text {MSMS }} \mathbf{( \% )}$ & $L_{\text {n,S-BDO }}$ & $L_{\text {n,MS-BDO }}$ & $R$ \\
\hline P(BS-BMS)10\% & 77.3 & 19.4 & 3.3 & 9.0 & 1.3 & 0.88 \\
P(BS-BMS)20\% & 53.7 & 36.6 & 9.7 & 3.9 & 1.5 & 0.92 \\
P(BS-BMS)30\% & 43.9 & 40.3 & 15.9 & 3.2 & 1.8 & 0.87 \\
P(BS-BMS)50\% & 32.2 & 47.6 & 20.2 & 2.3 & 1.9 & 0.96 \\
\hline
\end{tabular}

\subsection{Thermal Properties and Crystal Structures of P(BS-BMS) Copolymers}

The melting and crystallization behavior of copolymer samples were recorded by DSC. The cooling and second heating curves are shown in Figure $4 \mathrm{a}, \mathrm{b}$, and the corresponding thermal parameters including melting temperature $\left(T_{\mathrm{m}}\right)$, melting enthalpy $\left(\Delta H_{\mathrm{m}}\right)$, crystallization temperature $\left(T_{\mathrm{c}}\right)$ and crystallinity degree $\left(X_{\mathrm{c}}\right)$ are listed in Table 3 . It can be found that the crystallization behavior of $\mathrm{P}(\mathrm{BS}-\mathrm{BMS})$ is closely related to the molecular composition and sequence distribution.

(a)

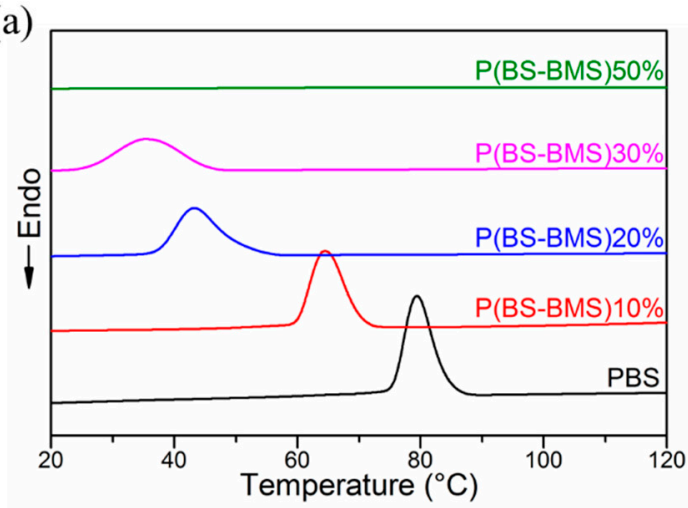

(c)

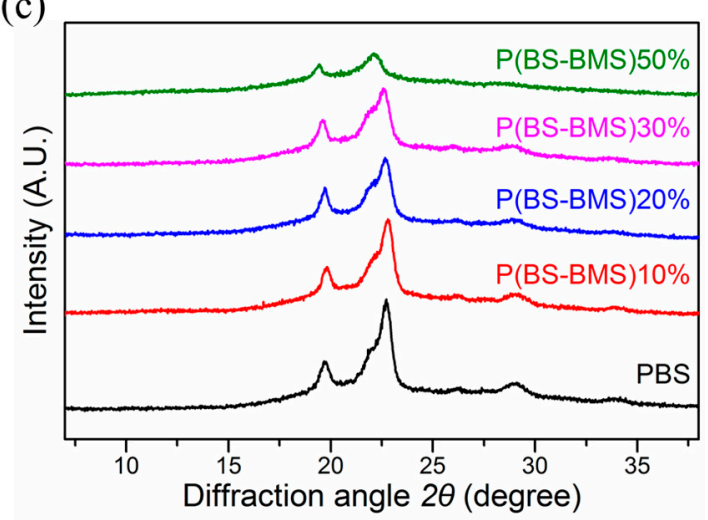

(b)

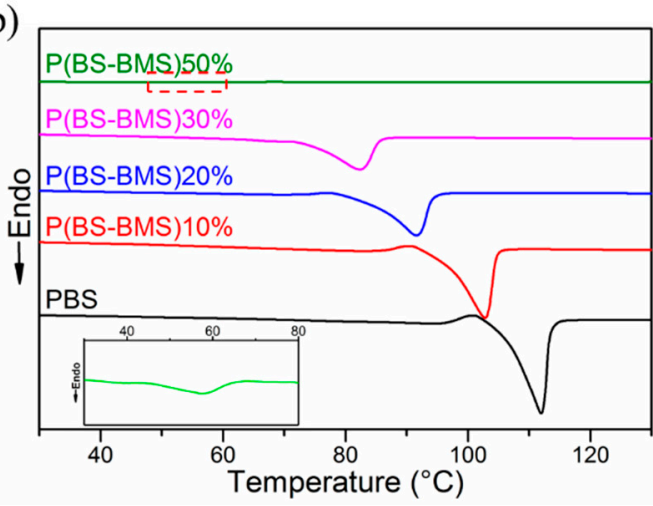

(d)

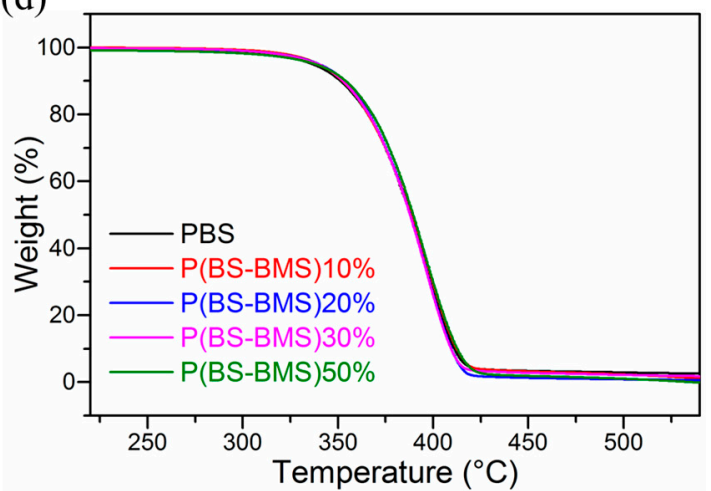

Figure 4. DSC curves of pure PBS and P(BS-BMS) copolymers during (a) first cooling from melt at a cooling rate of $10^{\circ} \mathrm{C} / \mathrm{min}$ and $(\mathbf{b})$ second heating process at a heating rate of $10^{\circ} \mathrm{C} / \mathrm{min}$ (inner figure is magnified second heating curve of $\mathrm{P}(\mathrm{BS}-\mathrm{BMS}) 50 \%$ ); (c) WAXD patterns of pure $\mathrm{PBS}$ and $\mathrm{P}(\mathrm{BS}-\mathrm{BMS})$ copolymers; (d) TGA curves of pure PBS and P(BS-BMS) copolymers at a heating rate of $10^{\circ} \mathrm{C} / \mathrm{min}$ under $\mathrm{N}_{2}$.

During the cooling procedure, samples with PBMS molar ratio ranging from 0 to $30 \%$ are able to crystallize, while P(BS-BMS)50\% doesn't show an exothermic peak which means it maintains an amorphous state at that procedure. On the other hand, former four samples only show a single crystallization peak, which is mainly attributed to crystallization of PBS segment. This crystallinity result is also confirmed by the WAXD test. As shown in Figure 4c, the pure PBS shows three main diffraction peaks at $19.6^{\circ}, 22.0^{\circ}$, and $22.8^{\circ}$, corresponding to (020), (021), and (110) reflection planes of $\alpha$-form crystal, respectively. The ratio of PBMS increase to $50 \%$, the samples exhibit three diffraction 
peaks at the same positions compared to the pure PBS. It means that only PBS segment in the copolymer can crystallize and also MSA does not influence the PBS crystal structure. In addition, pure PBS owns the highest crystallization temperature at $79.4^{\circ} \mathrm{C}$, which gradually decreases in $\mathrm{P}$ (BS-BMS) copolymers to $64.6{ }^{\circ} \mathrm{C}, 43.4{ }^{\circ} \mathrm{C}, 38.2{ }^{\circ} \mathrm{C}$ in $\mathrm{P}(\mathrm{BS}-\mathrm{BMS}) 10 \%$, $\mathrm{P}$ (BS-BMS) $20 \%$, and $\mathrm{P}(\mathrm{BS}-\mathrm{BMS}) 30 \%$, respectively. It indicates that introduction of MSA monomer will weaken the crystallization ability of copolymers because there is a chiral carbon atom attached to the side methyl group in MSA unit.

Table 3. Thermal parameters of pure PBS and P(BS-BMS) copolymers.

\begin{tabular}{|c|c|c|c|c|c|c|}
\hline \multirow{2}{*}{ Sample } & \multirow{2}{*}{$T_{\mathrm{m}}\left({ }^{\circ} \mathrm{C}\right)$} & \multirow{2}{*}{$\Delta H_{\mathrm{m}}(\mathrm{J} / \mathrm{g})$} & \multirow{2}{*}{$T_{\mathrm{c}}\left({ }^{\circ} \mathrm{C}\right)$} & \multirow{2}{*}{$X_{\mathrm{c}}(\%)^{a}$} & \multicolumn{2}{|c|}{ Thermal Degradation $\left({ }^{\circ} \mathrm{C}\right)$} \\
\hline & & & & & $T_{\mathrm{d}, 5}$ & $T_{\mathrm{d}, \max }$ \\
\hline PBS & 112.0 & 64.3 & 79.4 & 58.2 & 337.7 & 398.3 \\
\hline P(BS-BMS) $10 \%$ & 102.8 & 54.2 & 64.6 & 49.1 & 340.0 & 397.6 \\
\hline P(BS-BMS) $20 \%$ & 91.6 & 48.0 & 43.4 & 43.5 & 339.9 & 399.4 \\
\hline P(BS-BMS) $30 \%$ & 82.4 & 41.0 & 35.4 & 37.1 & 339.5 & 398.1 \\
\hline P(BS-BMS) $50 \%$ & 58.3 & 0.2 & - & 0.2 & 337.1 & 399.1 \\
\hline
\end{tabular}

${ }^{a}$ The degree of crystallinity $\left(X_{\mathrm{c}}\right)$ was calculated from the DSC results, $\Delta H_{0}(\mathrm{PBS})=110.4(\mathrm{~J} / \mathrm{g})[31]$.

During the second heating scan, all crystalline samples own single melting point, which shifts from $112.0{ }^{\circ} \mathrm{C}$ for pure PBS to $82.4{ }^{\circ} \mathrm{C}$ for P(BS-BMS) $30 \%$ copolymer. As shown in inner curve of Figure $4 \mathrm{~b}$, it shows an extremely weak melting behavior at $58.3^{\circ} \mathrm{C}$ for $\mathrm{P}(\mathrm{BS}-\mathrm{BMS}) 50 \%$. These decrease in $T_{\mathrm{m}}$ and crystallinity are due to the formation of imperfect crystals ascribed to the shortened sequence length of PBS from random copolymerization which indicates the introduction of MSA monomer can result in a significant impact on the melting point and crystallinity.

\subsection{Thermal Stability and Biodegradation of P(BS-BMS) Copolymers}

The thermal stability of P(BS-BMS) copolymers was measured by TGA in nitrogen atmosphere, which is a crucial property for the applicability of aliphatic polyesters. The recorded thermogravimetric curves of pure PBS and P(BS-BMS) copolymers are presented in Figure 4d. And both the decomposition temperature at $5 \%$ weight loss $\left(T_{\mathrm{d}, 5}\right)$ and that at maximum rate $\left(T_{\mathrm{d}, \max }\right)$ are listed in Table 3 . The $T_{\mathrm{d}, 5}$ and $T_{\mathrm{d} \text {,max }}$ of pure PBS and P(BS-BMS) copolymers are ranging from 337.1 to $340.0^{\circ} \mathrm{C}$ and 397.6 to $399.4{ }^{\circ} \mathrm{C}$, respectively. It is observed that the introducing of MSA instead of SA hardly affects the thermal stability of $\mathrm{P}$ (BS-BMS) copolymers, which means that these copolymers have nearly composition independent $T_{\mathrm{d}, 5}$ and $T_{\mathrm{d} \text {,max }}$. It is mainly because there is no change in the thermal decomposition mechanism while introducing the MSA monomer, which has little influence on the stability of ester bonds and polymer molecular chains.

Biodegradability has profound and significant influences for the application of biodegradable materials. In order to investigate the biodegradability of P(BS-BMS) copolymers, the enzymatic degradation experiments were executed with film samples. As shown in Figure $5 \mathrm{a}$, the weight loss ratio of $\mathrm{P}$ (BS-BMS) copolymers and pure $\mathrm{PBS}$ which were immersed in lipase medium for different time intervals is recorded. It can be observed that the MSA proportion of copolymerization greatly affects the rate of weight loss. As the MSA content increases, the weight loss increases obviously. In the pure PBS and P(BS-BMS)10\% samples, there was no significant weight loss after 12 days, as a comparison, when the PBMS content is increasing to $50 \%$, the weight of the sample remained only $31.7 \%$ of the original after 12 days. The specific weight loss data of each sample is listed in Table S1. After 12 days, the $\mathrm{P}(\mathrm{BS}-\mathrm{BMS}) 50 \%$ films have been partially broken into pieces, which led that it was hard to be weighed anymore. It is well known that the high amorphous content can promote the degradation rate of polyesters and the initial degradation usually begin in the amorphous phase. It is mainly due to the different ability of the enzyme to bind the active site of amorphous region and crystalline region. The crystalline regions are closed-packed while the amorphous regions are relatively loose. As a result, the amorphous regions are easier for small molecules like water to penetrate and enzyme to attach, 
which leads to the amorphous regions being more prone to degradation. As a control, the weight loss of the P(BS-BMS)50\% sample film in the pure phosphate buffer solution (without lipase) was also investigated. As shown in Figure $5 b$, unlike the severe degradation of the film in the enzyme phosphate buffer, the weight of the P(BS-BMS) $50 \%$ sample film doesn't decrease substantially in the pure phosphate buffer. This result indicates that the P(BS-BMS) copolymer doesn't degrade rapidly in phosphate buffer without enzyme promotion.
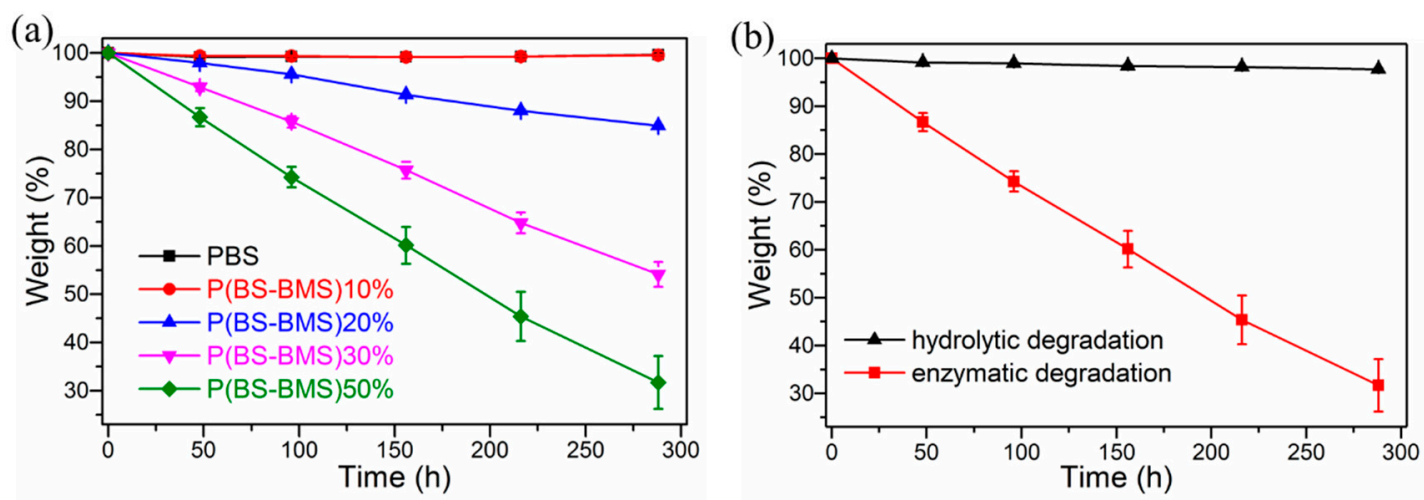

Figure 5. Weight losses of (a) pure PBS and P(BS-BMS) copolymer films in enzymatic degradation environment and (b) P(BS-BMS)20\% films in enzymatic degradation and hydrolytic degradation environment, respectively.

The molecular weight test of $\mathrm{P}$ (BS-BMS) copolymers in enzyme degradation solution was also carried out with different time intervals. The detailed data were listed in Table S2. As shown in Figures S1 and S2, the molecular weight of the residual copolymer film shows a decrease trend with time, and the decreasing rate is accelerated as the MSA ratio increases. It can be seen that although the weight of residual PBS film was not obviously reduced in the degradation test, its molecular weight has decreased to the original $92.9 \%$ after 12 days.

To gain more insight into the degradation behavior of $\mathrm{P}$ (BS-BMS) copolymers, the morphological observation is helpful to understand how the copolymer degrades during the test. Figure 6 presents the surface morphology evolution of the PBS, P(BS-BMS)10\%, 20\%, 50\% film samples during enzymatic degradation process. It shows that the surfaces of all the sample films appear smooth in the beginning. As we can see, during the 12 days of degradation process, there was no significant change in the surface of the PBS film, while for P(BS-BMS)10\% film, the surface was slightly roughed after immersed in the enzyme buffer solution, which indicates that the $\mathrm{P}(\mathrm{BS}-\mathrm{BMS}) 10 \%$ sample had slight degradation with the unobvious weight loss. Conversely, for P(BS-BMS)50\% film sample, the surface of sample film became rough quickly and many small holes ranging from 1 to $10 \mu \mathrm{m}$ appeared. Further, the pores were enlarged to form small fragments which contained both amorphous and crystalline regions removing from the film in the degradation of the enzyme buffer solution, and finally, the sample was no longer a whole and became into pieces. For P(BS-BMS)20\%, we could observe more details of the degradation process. After the corrosion of the enzymatic degradation solution, the clear spherulites presented. It proves that the degradation rate of the amorphous regions is much faster than that of the crystallization regions, which ultimately leads to the retention of a relatively complete cluster-like morphology of crystallization regions. From the above, the SEM observations are consistent with the weight loss results, indicating that the increase of PBMS content can accelerate the rate of enzyme degradation. From the results of the above enzymatic degradation test showed that for P(BS-BMS), a fully biodegradable material, we could control the degradation rate of P(BS-BMS) copolymers by changing the content of the MSA. 

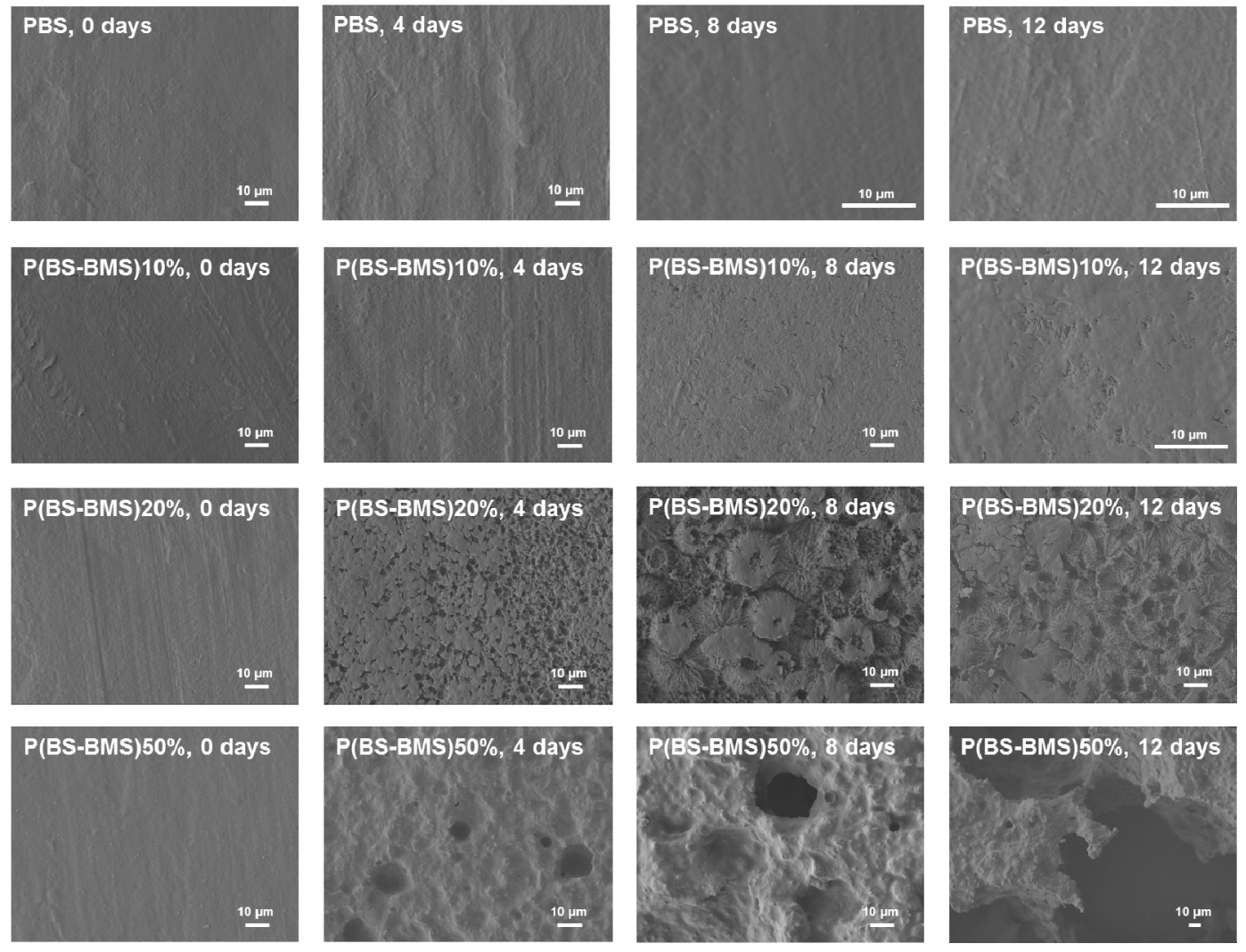

Figure 6. The surface changes of PBS, P(BS-BMS)10\%, P(BS-BMS)20\%, P(BS-BMS)50\% during enzymatic degradation test at different time intervals by SEM.

\subsection{Preparation of the Av-Loaded Delivery Systems Based on P(BS-BMS) Copolymers}

Carrier particle size has a great influence on drug release rate. Many studies have shown that as the particle size of drug-carrying microspheres decreases, the surface area increases, and small molecules are easy to pass through the carrier, leading to the increase of drug release rate. Besides, excellent particle size uniformity and dispersion can achieve efficient drug utilization and controlled release. As illustrated in Scheme 2, the PME method was used to prepare Av-loaded microspheres based on P(BS-BMS) copolymers by using SPG membrane with pore size of $5.4 \mu \mathrm{m}$. Compared with mechanical stirring, this method can efficiently obtain products with uniform sizes. As listed in Table 4, the Av-loaded microparticles based on different copolymers were obtained with actual size ranging from $1.31 \mu \mathrm{m}$ to $1.84 \mu \mathrm{m}$ with narrow size distribution $(P D I<1.3)$. No heating in the entire preparation process is another advantage of PME method, which avoids degradation of pesticides under high temperature conditions. Submicron-level pesticide formulations can improve the dispersibility of poorly soluble pesticide molecules and enhance the effective utilization of the pesticide.

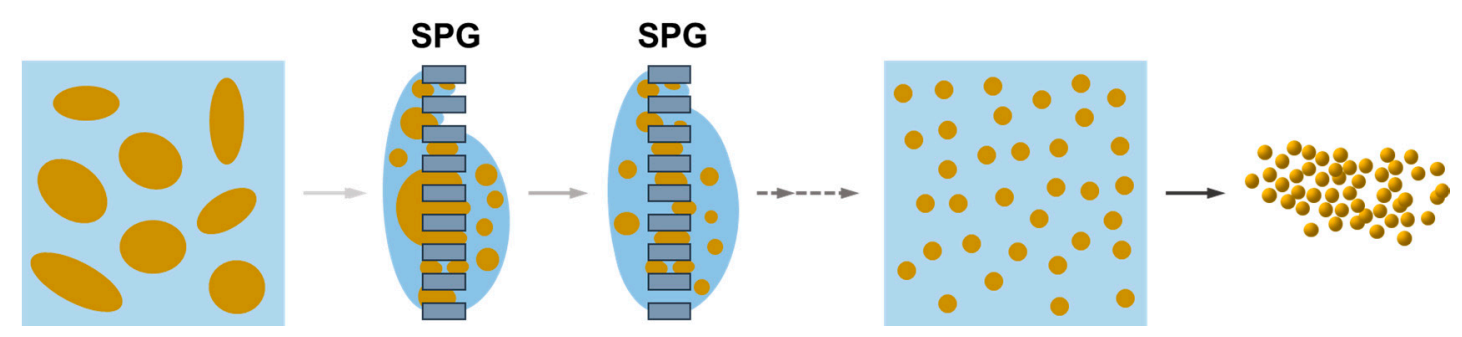

Scheme 2. Preparation of pesticide-loaded microparticles process by premix membrane emulsification (PME) method. SPG: Shirasu Porous Glass membrane. 
Table 4. Parameters of pesticide-loaded microparticle size and release performance.

\begin{tabular}{cccccccc}
\hline Sample & Size $(\mu \mathrm{m})$ & PDI & $\begin{array}{c}\text { Theoretical Loading } \\
\text { Content (\%) }\end{array}$ & $\begin{array}{c}\text { Measured Loading } \\
\text { Content (\%) }\end{array}$ & $\begin{array}{c}\text { Entrapment } \\
\text { Efficiency (\%) }\end{array}$ & $n$ & $r^{2}$ \\
\hline PBS/Av-2/1 & 1.84 & 1.24 & 33.3 & 26.6 & 79.9 & 0.62 & 0.99 \\
P(BS-BMS)10\%/Av-2/1 & 1.32 & 1.27 & 33.3 & 28.2 & 84.7 & 0.40 \\
P(BS-BMS)20\%/Av-2/1 & 1.31 & 1.24 & 33.3 & 29.5 & 88.5 & 0.98 \\
P(BS-BMS)30\%/Av-2/1 & 1.54 & 1.12 & 33.3 & 26.2 & 78.7 & 0.42 & 0.99 \\
P(BS-BMS)50\%/Av-2/1 & 1.61 & 1.21 & 33.3 & 22.5 & 67.6 & 0.99 \\
\hline
\end{tabular}

The morphology of the microparticles is another important factor affecting the drug release rate. The morphology of Av-loaded microparticles based on P(BS-BMS) copolymer and pure PBS was observed by SEM as shown in Figure 7. As we can see in Figure 7 (the upper row), all the Av-loaded microparticles based on P(BS-BMS) $10 \%-50 \%$ exhibit an approximately spherical shape with some small holes on the surface. These defects on the surface mainly attribute to the phase separation during the solvent evaporation process. Unlike the above samples, the morphology of Av-loaded microparticles based on pure PBS exhibits an irregular shape with multiple folds on the surface structure instead of smooth spherical microparticles (as indicated by the red arrows). In the solvent evaporation and phase separation process, since the solubility of the pure PBS in chloroform is much lower than that of the P(BS-BMS) copolymer, the PBS system separates out from the organic phase earlier. The initial formed PBS shell is too thin to support the formation of microparticles, and then collapses to form irregular microparticles with large wrinkles. In addition, the irregular shape with rough surface is another advantageous for the retention of the Av-loaded system on the leaves compared to other systems with the intact spherical shape. The depression on the surface of microparticle also helps the Av-loaded microparticles to hang on the fluff on the surface of the leaves.

\section{Before release:}
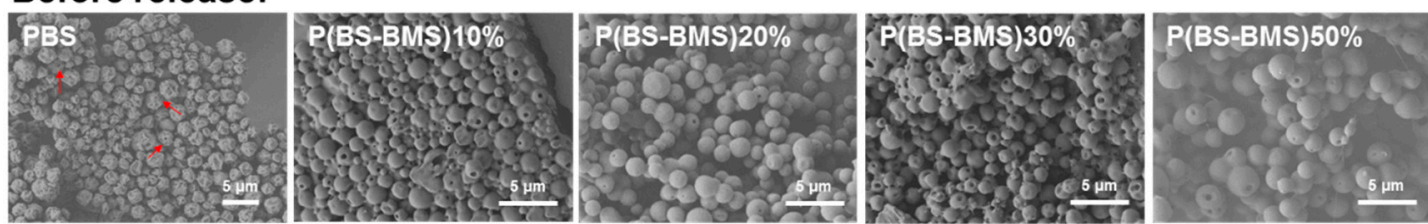

\section{After release:}
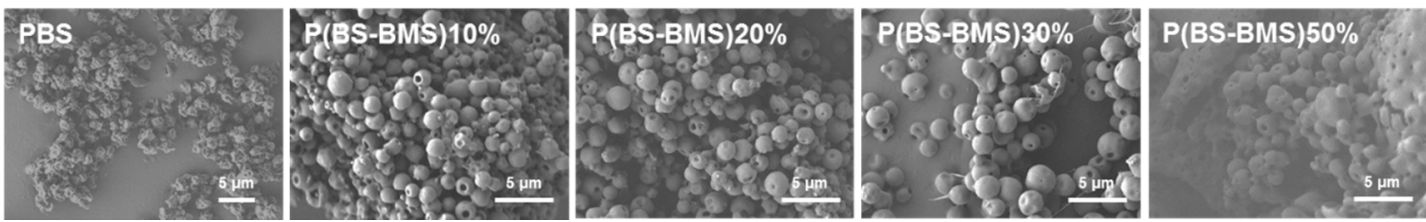

Figure 7. Morphology of different Av-loaded microparticles before and after release in $240 \mathrm{~h}$.

\subsection{Av entrapment Efficiency and Encapsulation State}

Loading content and entrapment efficiency are two important indicators for evaluating overall performance pesticide release systems. The high drug loading and entrapment efficiency not only reduces the waste of active ingredients during the preparation process but also reduces environmental pollution and personal injury caused by excessive use during actual application. The loading content and entrapment efficiency of all formulations are listed in Table 4, which indicates that the entrapment efficiency of each form is higher than $67 \%$. As the crystallization ability of the P(BS-BMS) copolymers decreases, the entrapment efficiency of the Av ingredient approximately tends to decrease. It mainly because the crystallization regions can limit the diffusion of the Av molecules resulting in being trapped in microparticles during the solvent evaporation process.

The DSC and wide angle X-ray diffraction test were used to detect the physical state of the Av-loaded systems including carrier polymers and active ingredients. As shown in Figure 8a, the DSC results shows only the PBS segment melting peak appears in the first heating curve of the Av-loaded 
microparticles, which means that the pesticide molecules were dispersed in the polymer in an amorphous state. Furthermore, the melting peak of the PBS crystal moves to the low temperature region and the melting range becomes wider, which indicates that the introduction of the pesticide molecules affects the PBS segments into the lattice. As shown in Figure 8b, a large number of sharp diffraction peaks are detected with crystalline Av molecules. As a comparison, these characteristic peaks attributed to Av were not detected in P(BS-BMS)20\%/Av-2/1 system, whereas only the characteristic diffraction peaks belonging to PBS segment were revealed. This is consistent with the above DSC results, the introduction of the Av molecules does not change the crystalline form of the P(BS-BMS) matrix.

(a)

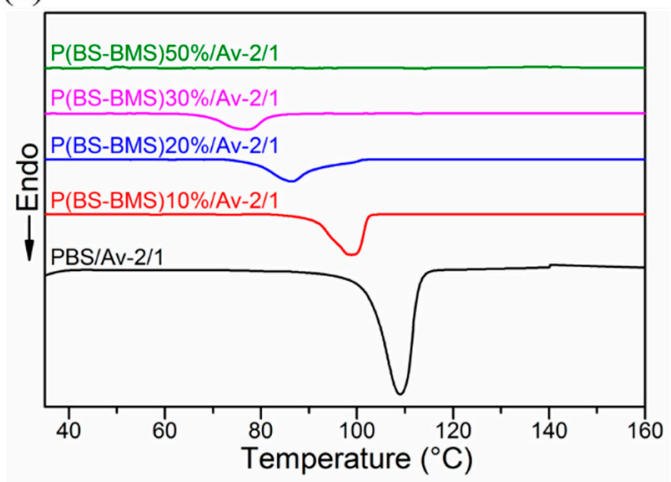

(b)

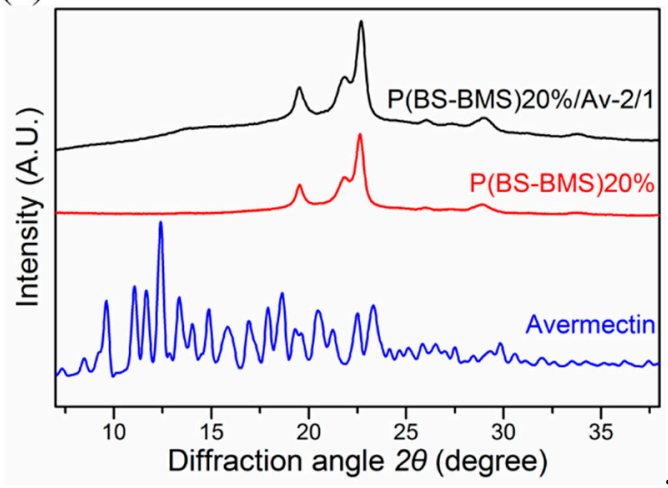

Figure 8. (a) DSC curves of Av-loaded microparticles based on pure PBS and P(BS-BMS) copolymers during first heating process at a rate of $10{ }^{\circ} \mathrm{C} / \mathrm{min}$; (b) WAXD patterns of Avermectin, $\mathrm{P}(\mathrm{BS}-\mathrm{BMS}) 20 \%$ and $\mathrm{P}(\mathrm{BS}-\mathrm{BMS}) 20 \% / \mathrm{Av}-2 / 1$, respectively.

\subsection{Control Release of $A v$}

In order to study the pesticide release mechanism, the release behavior of Av-loaded microparticles based on different P(BS-BMS) copolymers and pure PBS was investigated. As shown in Figure 9a, compared to Av commercial emulsion formulations, all microparticle forms exhibit a relatively slow release rate, which means that in the actual application process, it can achieve long-term stable release and realize the purpose of reducing the pesticides usage amount and microplastic pollution. Additionally, all the drug release process presents an initial burst release at first followed by a sustained release for longer period. During the initial release process, the Av active ingredients which are adsorbed in the surface layer of the microparticles can be dissolved in the release environment quickly by directly contacting the solvent, resulting in the rapid release process. After that, the Av molecules inside the microparticles slowly diffuses into the medium over time. The Korsmeyer-Peppas equation is considered to fit the Av-release data in order to analyze changes in the drug release process system:

$$
\frac{Q_{t}}{Q_{\infty}}=k t^{n}
$$

where the $\frac{Q}{Q_{\infty}}$ is the Av release ratio, $k$ is a kinetic constant, $t$ is the release time and the $\mathrm{n}$ is diffusion exponent which indicates the drug release mechanism. For sphere-form system, $n=0.43$ means Fick diffusion and higher values of $n$, between 0.43 and 0.85 or $n=0.85$ mean mass transfer like dynamic swelling or degradation of matrix following a non-Fickian model. It must note that the part with the $\frac{Q_{t}}{Q_{\infty}}<0.6$ of the release curve should only be used for determination of the exponent $n$. The fitting curve of $\mathrm{P}$ (BS-BMS)20\%/Av-2/1 microparticles release process according to Korsmeyer-Peppas equation is shown in Figure 9b (other fitting curves based on P(BS-BMS) copolymers and pure PBS are shown in Figures S3-S6, respectively), and more detailed parameters are listed in Table 4. The correlation coefficient $\left(r^{2}\right)$ of all samples is higher than 0.97 which means the release curve matched well with the Korsmeyer-Peppas equation. For Av-loaded microparticles based on P(BS-BMS) $10 \%$, $\mathrm{P}(\mathrm{BS}-\mathrm{BMS}) 20 \%$ and $\mathrm{P}(\mathrm{BS}-\mathrm{BMS}) 30 \%, n$ is nearly 0.43 , which indicates that the Av release basically 
follows Fick diffusion in these systems. In other two systems, $n$ slightly larger than 0.43 illustrates some changes of polymer matrix accelerate the diffusion rate of Av molecules except following the Fick diffusion. In order to better explain the changes in the matrix, the morphology of the Av-loaded microparticles after drug release was also observed by SEM. As shown in Figure 7 (the lower row), for the Av-loaded system based on pure PBS matrix, further structural collapse and damage of the microparticles can be clear observed, which can promote the penetration of the release solution and the rate of Av release. As for $\mathrm{P}(\mathrm{BS}-\mathrm{BMS}) 50 \%$, the change of morphology is different from the PBS/Av system. In this systems, the microparticles adhered to each other during release process. This indicates that due to the increasing proportion of amorphous regions in the polymer matrix, a portion of the matrix can swell or deform in the release medium to accelerate the Av-release rate during the release of Av.

(a)

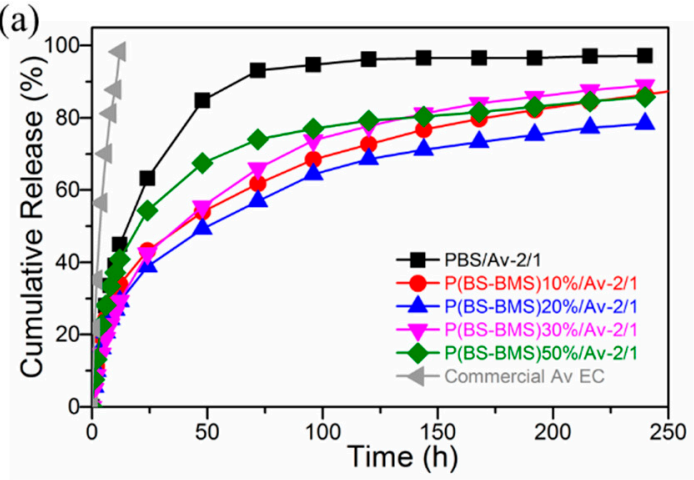

(b)

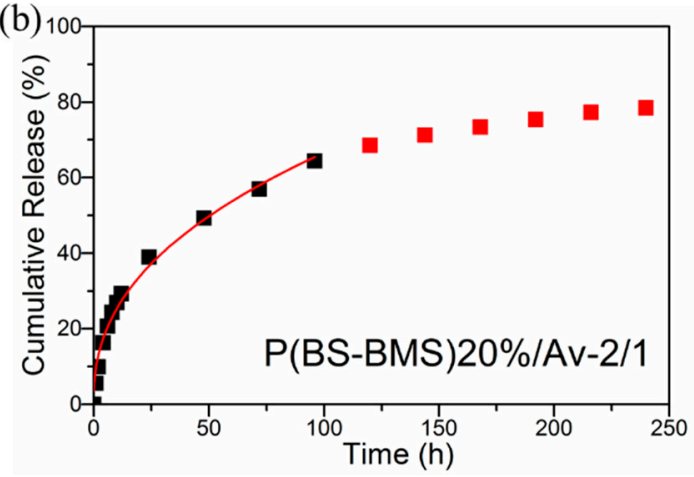

Figure 9. (a) the release behavior of commercial Av form and Av-loaded microparticles based on different P(BS-BMS) copolymers; (b) fitting curve of P(BS-BMS)20\%/Av-2/1 release profile according to Korsmeyer-Peppas equation.

Therefore, the crystallinity of the matrix is a key factor affecting the rate of drug release. For high crystallinity polymers like pure PBS, folded-surface morphology can be formed during the preparation process. This morphology increases the surface area met with the release medium, besides during the release process, the loose particulate structure tends to collapse even damage and thereby promote drug release. As for high amorphousness polymers, diffusion of the active ingredient is much easier in the amorphous region owing to higher mobility of molecular chains in amorphous state than crystal state in the release medium. Additionally, much easier penetration of release medium through the amorphous regions also accelerates the drug release rate. A relatively slow release drug system can be obtained based on a polymer matrix with proper crystallinity. The lamellae structure may limit the diffusion of small molecules and chain movement attributed to its poor motion ability which leads to prolonged release pathway of Av molecules.

\section{Conclusions}

A series of $\mathrm{P}$ (BS-BMS) copolymers were successfully prepared via direct two-step esterification and polycondensation method. The P(BS-BMS) copolyesters presented widely tunable properties including melting temperature and degree of crystallinity, ranging from high crystallinity plastics to flexible amorphous polymers. As the MSA content increased, the proportion of the amorphous region of the copolymer increased gradually, which made the copolymer easier for microorganisms and degrading enzymes to adhere to the reaction sites, resulting in a significant acceleration in biodegradability. This was mainly because the side methyl group in the MSA unit destroyed the regularity of the segment and prevented the segment from being discharged into the crystal lattice. At the same time, the thermal stability of P(BS-BMS) copolymers showed no obvious change with the increasing of MSA content. Then we successfully prepared Av-loaded microparticles based on P(BS-BMS) copolymers with uniform size by PME method and these Av-loaded systems showed an 
initial burst release followed by a significantly sustained release over 10 days in a methanol/water $(40 / 60, v / v)$ mixture. The effects of crystallinity on the morphology of microparticles and drug release profile were also discussed, which showed the proper crystallinity could be used to control release kinetics to meet practical requirements of drug release. It was worth mentioning that the P(BS-BMS) copolymers could be completely biodegraded so as not to bring additional micro-plastic pollution pressure to the water and soil environment when they were applied to agriculture field.

Supplementary Materials: The following are available online at http:/www.mdpi.com/1996-1944/12/9/1507/s1, Figure S1: $M_{n}$ losses of pure PBS and P(BS-BMS) copolymer residual films in enzymatic degradation environment in different time intervals. Figure S2: GPC curves of P(BS-BMS) copolymers and pure PBS after 12 days degradation process. Figure S3: Fitting curve of P(BS-BMS)10\%/Av-2/1 release profile according to Korsmeyer-Peppas equation. Figure S4: Fitting curve of $\mathrm{P}(\mathrm{BS}-\mathrm{BMS}) 30 \% / \mathrm{Av}-2 / 1$ release profile according to Korsmeyer-Peppas equation. Figure S5: Fitting curve of $\mathrm{P}(\mathrm{BS}-\mathrm{BMS}) 50 \% / \mathrm{Av}-2 / 1$ release profile according to Korsmeyer-Peppas equation. Figure S6: Fitting curve of PBS/Av-2/1 release profile according to Korsmeyer-Peppas equation. Table S1: Weight loss data of pure PBS and P(BS-BMS) copolymers during enzyme degradation test. Table S2: Molecular weight data of pure PBS and P(BS-BMS) copolymers by GPC test.

Author Contributions: Conceptualization, J.H., and B.G.; Methodology, J.H., and J.S.; Software, J.H., and Z.X.; Validation, J.H., and J.X.; Formal Analysis, J.H.; Investigation, J.H.; Resources, J.X., and B.G.; Data Curation, J.H.; Writing-Original Draft Preparation, J.H.; Writing-Review \& Editing, J.X., and B.G.; Visualization, J.H.; Supervision, B.G.; Project Administration, J.X. and B.G.; Funding Acquisition, J.X., and B.G.

Funding: This work was financially supported by the National Natural Science Foundation of China (Grant No. 51673110, 51473085), the Joint Funds of the National Natural Science Foundation of China (Grant No. U1862205), Tsinghua University-Suzhou Innovation Leading Program (Grant No. 2016SZ0315) and Tsinghua University Scientific Research Project (Grant No.2018Z05JDX003).

Conflicts of Interest: The authors declare no conflict of interest.

\section{References}

1. Kong, X.; Qi, H.; Curtis, J.M. Synthesis and characterization of high-molecular weight aliphatic polyesters from monomers derived from renewable resources. J. Appl. Sci. 2014, 131, 4401-4404. [CrossRef]

2. Dai, J.; Ma, S.; Teng, N.; Dai, X.; Shen, X.; Wang, S.; Liu, X.; Zhu, J. 2,5-Furandicarboxylic Acid- and Itaconic Acid-Derived Fully Biobased Unsaturated Polyesters and Their Cross-Linked Networks. Ind. Eng. Chem. 2017, 56, 2650-2657. [CrossRef]

3. Trotta, J.T.; Watts, A.; Wong, A.R.; LaPointe, A.M.; Hillmyer, M.A.; Fors, B.P. Renewable Thermosets and Thermoplastics from Itaconic Acid. ACS Sustainable Chem. Eng. 2019, 7, 2691-2701. [CrossRef]

4. Bastioli, C. Handbook of Biodegradable Polymers; Rapra Technology Limited: Shropshire, UK, 2005.

5. Tachibana, Y.; Yamahata, M.; Kimura, S.; Kasuya, K.I. Synthesis, physical properties, and biodegradability of Bio-based Poly(butylene succinate-co-butylene oxabicyclate). ACS Sustain. Chem. Eng. 2018, 6, 10806-10814. [CrossRef]

6. Liu, T.; Hao, C.; Wang, L.; Li, Y.; Liu, W.; Xin, J.; Zhang, J. Eugenol-Derived Biobased Epoxy: Shape Memory, Repairing, and Recyclability. Macromolecules 2017, 50, 8588-8597. [CrossRef]

7. Liu, T.; Guo, X.; Liu, W.; Hao, C.; Wang, L.; Hiscox, W.C.; Liu, C.; Jin, C.; Xin, J.; Zhang, J. Selective cleavage of ester linkages of anhydride-cured epoxy using a benign method and reuse of the decomposed polymer in new epoxy preparation. Green Chem. 2017, 19, 4364-4372. [CrossRef]

8. Zhang, S.; Liu, T.; Hao, C.; Wang, L.; Han, J.; Liu, H.; Zhang, J. Preparation of a lignin-based vitrimer material and its potential use for recoverable adhesives. Green Chem. 2018, 20, 2995-3000. [CrossRef]

9. Altuna, F.I.; Pettarin, V.; Williams, R.J. Self-healable polymer networks based on the cross-linking of epoxidised soybean oil by an aqueous citric acid solution. Green Chem. 2013, 15, 3360-3366. [CrossRef]

10. Shi, K.; Bai, Z.; Su, T.; Wang, Z. Selective enzymatic degradation and porous morphology of poly(butylene succinate)/poly(lactic acid) blends. Int. J. Biol. Macromol. 2019, 126, 436-442. [CrossRef]

11. Kitamoto, H.; Yoshida, S.; Koitabashi, M.; Yamamoto-Tamura, K.; Ueda, H.; Yarimizu, T.; Sameshima-Yamashita, Y. Enzymatic degradation of poly-butylene succinate-co-adipate film in rice husks by yeast Pseudozyma antarctica in indoor conditions. J. Biosci. Bioeng. 2018, 125, 199-204. [CrossRef]

12. Abe, M.; Kobayashi, K.; Honma, N.; Nakasaki, K. Microbial degradation of poly(butylene succinate) by Fusarium solani in soil environments. Degrad. Stab. 2010, 95, 138-143. [CrossRef] 
13. Shinozaki, Y.; Morita, T.; Cao, X.H.; Yoshida, S.; Koitabashi, M.; Watanabe, T.; Kitamoto, H.K. Biodegradable plastic-degrading enzyme from Pseudozyma antarctica: Cloning, sequencing, and characterization. Appl. Microbiol. Biotechnol. 2013, 97, 2951-2959. [CrossRef]

14. Huang, Z.; Qian, L.; Yin, Q.; Yu, N.; Liu, T.; Tian, D. Biodegradability studies of poly(butylene succinate) composites filled with sugarcane rind fiber. Polym. Test. 2018, 66, 319-326. [CrossRef]

15. Shi, K.; Liu, Y.; Hu, X.; Su, T.; Li, P.; Wang, Z. Preparation, characterization, and biodegradation of poly(butylene succinate)/cellulose triacetate blends. Int. J. Boil. Macromol. 2018, 114, 373-380. [CrossRef]

16. Wang, D.; Lu, X.; Qu, J. Role of In situ thermal-reduced graphene oxide on the morphology and properties of biodegradable poly(Lactic acid)/poly(butylene succinate) blends. Polym. Compos. 2017, 39, 3057-3065. [CrossRef]

17. Zhou, W.; Wang, X.; Yang, B.; Xu, Y.; Zhang, W.; Zhang, Y.; Ji, J. Synthesis, physical properties and enzymatic degradation of bio-based poly(butylene adipate-co-butylene furandicarboxylate) copolyesters. Degrad. Stab. 2013, 98, 2177-2183. [CrossRef]

18. Tachibana, Y.; Masuda, T.; Funabashi, M.; Kunioka, M. Chemical Synthesis of Fully Biomass-Based Poly(butylene succinate) from Inedible-Biomass-Based Furfural and Evaluation of Its Biomass Carbon Ratio. Biomacromolecules 2010, 11, 2760-2765. [CrossRef]

19. Tserki, V.; Matzinos, P.; Pavlidou, E.; Vachliotis, D.; Panayiotou, C. Biodegradable aliphatic polyesters. Part I. Properties and biodegradation of poly(butylene succinate-co-butylene adipate). Polym. Degrad. Stab. 2006, 91, 367-376. [CrossRef]

20. Puchalski, M.; Szparaga, G.; Biela, T.; Gutowska, A.; Sztajnowski, S.; Krucińska, I. Molecular and Supramolecular Changes in Polybutylene Succinate (PBS) and Polybutylene Succinate Adipate (PBSA) Copolymer during Degradation in Various Environmental Conditions. Polymers 2018, 10, 251. [CrossRef]

21. Hongsriphan, N.; Pinpueng, A. Properties of Agricultural Films Prepared from Biodegradable Poly(Butylene Succinate) Adding Natural Sorbent and Fertilizer. J. Polym. Environ. 2019, 27, 434-443. [CrossRef]

22. Siwek, P.; Libik, A.; Kalisz, A.; Zawiska, I. The effect of biodegradable nonwoven direct covers on yield and quality of winter leek. Folia Hort. 2013, 25, 61-65. [CrossRef]

23. Khalil, H.A.; Banerjee, A.; Saurabh, C.K.; Tye, Y.Y.; Suriani, A.B.; Mohamed, A.; Paridah, M.T. Biodegradable Films for Fruits and Vegetables Packaging Application: Preparation and Properties. Food Eng. Rev. 2018, 10, 139-153. [CrossRef]

24. Chen, S.; Ma, C.; Zhang, G. Biodegradable polymers for marine antibiofouling: Poly( $\varepsilon$-caprolactone)/poly(butylene succinate) blend as controlled release system of organic antifoulant. Polymer 2016, 90, 215-221. [CrossRef]

25. Bi, S.; Tan, B.; Soule, J.L.; Sobkowicz, M.J. Enzymatic degradation of poly (butylene succinate-co-hexamethylene succinate). Degrad. Stab. 2018, 155, 9-14. [CrossRef]

26. Li, F.; Xu, X.; Hao, Q.; Li, Q.; Yu, J.; Cao, A. Effects of comonomer sequential structure on thermal and crystallization behaviors of biodegradable poly(butylene succinate-co-butylene terephthalate)s. J. Polym. Sci. Part B Polym. Phys. 2006, 44, 1635-1644. [CrossRef]

27. Heidarzadeh, N.; Rafizadeh, M.; Taromi, F.A.; Del Valle, L.J.; Franco, L.; Puiggalí, J. Biodegradability and biocompatibility of copoly(butylene sebacate-co-terephthalate)s. Degrad. Stab. 2017, 135, 18-30. [CrossRef]

28. Zeng, J.-B.; Huang, C.-L.; Jiao, L.; Lu, X.; Wang, Y.-Z.; Wang, X.-L. Synthesis and Properties of Biodegradable Poly(butylene succinate-co-diethylene glycol succinate) Copolymers. Ind. Eng. Chem. 2012, 51, 12258-12265. [CrossRef]

29. Zhang, Y.; Han, J.; Wu, S.; Qi, Z.; Xu, J.; Guo, B. Synthesis, physical properties and photodegradation of functional poly(butylene succinate) covalently linking UV stabilizing moieties in molecular chains. Colloids Surfaces A: Physicochem. Eng. Asp. 2017, 524, 160-168. [CrossRef]

30. Nikolic, M.S.; Poleti, D.; Djonlagic, J. Synthesis and characterization of biodegradable poly(butylene succinate-co-butylene fumarate)s. Eur. Polym. J. 2003, 39, 2183-2192. [CrossRef]

31. Li, C.; Xiao, Y.; Guan, G.; Zheng, L.; Wang, Z.; Wang, J.; Zhang, D. Novel Biodegradable and Double Crystalline Multiblock Copolymers Comprising of Poly(butylene succinate) and Poly( $\varepsilon$-caprolactone): Synthesis, Characterization, and Properties. Ind. Eng. Chem. 2012, 51, 7264-7272.

32. Wu, S.; Zhang, Y.; Han, J.; Xie, Z.; Xu, J.; Guo, B. Copolymerization with Polyether Segments Improves the Mechanical Properties of Biodegradable Polyesters. ACS Omega 2017, 2, 2639-2648. [CrossRef] 
33. Zhang, Y.; Dai, Z.-H.; Han, J.; Li, T.; Xu, J.; Guo, B. Interplay between crystallization and the Diels-Alder reaction in biobased multiblock copolyesters possessing dynamic covalent bonds. Polym. Chem. 2017, 8 , 4280-4289. [CrossRef]

34. Zheng, L.; Wang, Z.; Wu, S.; Li, C.; Zhang, D.; Xiao, Y. Novel Poly(butylene fumarate) and Poly(butylene succinate) Multiblock Copolymers Bearing Reactive Carbon-Carbon Double Bonds: Synthesis, Characterization, Cocrystallization, and Properties. Ind. Eng. Chem. 2013, 52, 6147-6155. [CrossRef]

35. Dai, Z.; Yang, Z.; Chen, Z.; Zhao, Z.; Lou, Y.; Zhang, Y.; Liu, T.; Fu, F.; Fu, Y.; Liu, X. Fully Biobased Composites of an Itaconic Acid Derived Unsaturated Polyester Reinforced with Cotton Fabrics. ACS Sustain. Chem. Eng. 2018, 6, 15056-15063. [CrossRef]

36. Panic, V.V.; Seslija, S.I.; Popovic, I.G.; Spasojevic, V.D.; Popovic, A.R.; Nikolic, V.B.; Spasojevic, P.M. Simple One-Pot Synthesis of Fully Biobased Unsaturated Polyester Resins Based on Itaconic Acid. Biomacromolecules 2017, 18, 3881-3891. [CrossRef] [PubMed]

37. Da Cruz, J.C.; de Castro, A.M.; Sérvulo, E.F.C. World market and biotechnological production of itaconic acid. Biotech 2018, 8, 138. [CrossRef] [PubMed]

38. Xie, T.; Gao, C.; Wang, C.; Shen, S.; Wu, Y. Application of Poly(butylenes 2-methylsuccinate) as Migration Resistant Plasticizer for Poly(vinyl chloride). Polym. Technol. Eng. 2014, 53, 465-471. [CrossRef]

39. Wu, Y.; Xie, Q.; Gao, C.; Wang, T.; Wang, C. Synthesis and Characterization of a Novel Aliphatic Polyester Based on Itaconic Acid. Polym. Eng. Sci. 2015, 54, 2515-2521. [CrossRef]

40. Li, T.; Lü, S.; Ji, Y.; Qi, T.; Liu, M. A biodegradable Fe-fertilizer with high mechanical property and sustainable release for potential agriculture and horticulture applications. New J. Chem. 2018, 42, 19129-19136. [CrossRef]

41. Tanan, W.; Panichpakdee, J.; Saengsuwan, S. Novel biodegradable hydrogel based on natural polymers: Synthesis, characterization, swelling/reswelling and biodegradability. Eur. J. 2019, 112, 678-687. [CrossRef]

42. Feng, D.; Bai, B.; Wang, H.; Suo, Y. Novel Fabrication of Biodegradable Superabsorbent Microspheres with Diffusion Barrier through Thermo-Chemical Modification and Their Potential Agriculture Applications for Water Holding and Sustained Release of Fertilizer. J. Agric. Food Chem. 2017, 65, 5896-5907. [CrossRef]

43. Geicu-Cristea, M.; Popa, M.E.; Miteluţ, A.C.; Dănăilă-Guidea, S.M.; Neaţă, G.; Burnichi, R.; Tănase, E.E.; Drăghici, M.C.; Popescu, P.A. Research on Agriculture Applications of Some Newly Developed Biobased Products. Agric. Agric. Sci. Procedia 2016, 10, 485-493. [CrossRef]

44. Puoci, F.; Iemma, F.; Spizzirri, U.G.; Cirillo, G.; Curcio, M.; Picci, N. Polymer in Agriculture: A Review. Am. J. Agric. Biol. Sci. 2008, 3, 299-314. [CrossRef]

45. K, S.; Ngouajio, M. Polyethylene and biodegradable mulches for agricultural applications: A review. Agron. Sustain. Dev. 2012, 32, 501-529.

46. Touchaleaume, F.; Martin-Closas, L.; Angellier-Coussy, H.; Chevillard, A.; Cesar, G.; Gontard, N.; Gastaldi, E. Performance and environmental impact of biodegradable polymers as agricultural mulching films. Chemosphere 2016, 144, 433-439. [CrossRef]

47. Lubkowski, K.; Smorowska, A.; Grzmil, B.; Kozłowska, A. Controlled-Release Fertilizer Prepared Using a Biodegradable Aliphatic Copolyester of Poly(butylene succinate) and Dimerized Fatty Acid. J. Agric. Food Chem. 2015, 63, 2597-2605. [CrossRef]

48. Yusoff, S.N.M.; Kamari, A.; Aljafree, N.F.A. A review of materials used as carrier agents in pesticide formulations. Int. J. Environ. Sci. Technol. 2016, 13, 2977-2994. [CrossRef]

49. Ding, K.; Yi, Y.; Shi, L.; Zhang, L.; Zeng, T.; Yin, Y. Synthesis of photoresponsive polymeric propesticide micelles based on PEG for the controlled release of a herbicide. Polym. Chem. 2016, 7, 899-904. [CrossRef]

50. Guan, W.; Zhang, W.; Tang, L.; Wang, Y.; Cui, H. Fabrication of novel avermectin nanoemulsion using polyurethane emulsifier with cleavable disulfide bonds. J. Agric. Food Chem. 2018, 66, 6569-6577. [CrossRef]

51. Nuruzzaman, M.; Rahman, M.M.; Liu, Y.; Naidu, R. Nanoencapsulation, Nano-guard for Pesticides: A New Window for Safe Application. J. Agric. Food Chem. 2016, 64, 1447-1483. [CrossRef]

52. Fenner, K.; Canonica, S.; Wackett, L.P.; Elsner, M. Evaluating pesticide degradation in the environment: Blind spots and emerging opportunities. Science 2013, 341, 752-758. [CrossRef] [PubMed]

53. Jia, X.; Sheng, W.-B.; Li, W.; Tong, Y.-B.; Liu, Z.-Y.; Zhou, F. Adhesive Polydopamine Coated Avermectin Microcapsules for Prolonging Foliar Pesticide Retention. ACS Appl. Mater. Interfaces 2014, 6, 19552-19558. [CrossRef] [PubMed]

54. Li, D.; Liu, B.; Yang, F.; Wang, X.; Shen, H.; Wu, D. Preparation of uniform starch microcapsules by premix membrane emulsion for controlled release of avermectin. Carbohydr. Polym. 2016, 136, 341-349. [CrossRef] 
55. Nazir, A.; Schroën, K.; Boom, R. Premix emulsification: A review. J. Membr. Sci. 2010, 362, 1-11. [CrossRef]

56. Wei, Y.; Wang, Y.; Wang, L.; Hao, D.; Ma, G. Fabrication strategy for amphiphilic microcapsules with narrow size distribution by premix membrane emulsification. Colloids Surf. B Biointerfaces 2011, 87, 399-408. [CrossRef] [PubMed]

57. Kou, X.; Li, Q.; Lei, J.; Geng, L.; Deng, H.; Zhang, G.; Ma, G.; Su, Z.; Jiang, Q. Preparation of molecularly imprinted nanospheres by premix membrane emulsification technique. J. Membr. Sci. 2012, 417, 87-95. [CrossRef]

58. Wei, Q.; Wei, W.; Lai, B.; Wang, L.-Y.; Wang, Y.-X.; Su, Z.-G.; Ma, G.-H. Uniform-sized PLA nanoparticles: Preparation by premix membrane emulsification. Int. J. Pharm. 2008, 359, 294-297. [CrossRef]

59. Zhang, B.; Yang, T.; Wang, Q.; Zhang, G.; Huo, J.; Huang, J.; Wang, L. Fabrication of uniform alginate-agarose microcapsules loading $\mathrm{FeSO} 4$ using water-oil-water-oil multiple emulsions system combined with premix membrane emulsification technique. Colloids Surfaces A Physicochem. Eng. Asp. 2016, 498, 128-138. [CrossRef]

60. Wang, Y.; Ono, H.; Ikeda, A.; Hori, N.; Takemura, A.; Yamada, T.; Tsukatani, T. 1H NMR and 13C NMR investigations of sequence distribution and tacticity in poly(vinyl alcohol-co-vinyl levulinate). Polymer 2006, 47, 7827-7834. [CrossRef]

61. Matsuda, H.; Asakura, T.; Miki, T. Triad Sequence Analysis of Poly(ethylene/butylene terephthalate) Copolymer Using1H NMR. Macromolecules 2002, 35, 4664-4668. [CrossRef]

62. Zhang, Y.; Feng, Z.; Feng, Q.; Cui, F. The influence of soft segment length on the properties of poly(butylene terephthalate-co-succinate)- $b$-poly(ethylene glycol) segmented random copolymers. Eur. J. 2004, 40, 1297-1308. [CrossRef]

63. Debuissy, T.; Pollet, E.; Avérous, L. Synthesis and characterization of biobased poly(butylene succinate- ran -butylene adipate). Analysis of the composition-dependent physicochemical properties. Eur. J. 2017, 87, 84-98. [CrossRef]

(C) 2019 by the authors. Licensee MDPI, Basel, Switzerland. This article is an open access article distributed under the terms and conditions of the Creative Commons Attribution (CC BY) license (http://creativecommons.org/licenses/by/4.0/). 